\title{
The role of NMDAR antibody in the etiopathogenesis of schizophrenia
}

\author{
This article was published in the following Dove Press journal: \\ Neuropsychiatric Disease and Treatment \\ 13 September 2016 \\ Number of times this article has been viewed
}

\section{Damla Timucin' \\ Osman Ozdemir ${ }^{2}$ \\ Mehmet Parlak ${ }^{3}$ \\ 'Department of Psychiatry, University of Health Sciences, Van Training and Research Hospital, Van, ${ }^{2}$ Department of Psychiatry, ${ }^{3}$ Department of Microbiology, Faculty of Medicine, Yuzuncu Yil University, Van, Turkey}

\begin{abstract}
Many authors have reported the presence of serum NMDAR antibodies in varying proportions of patients with schizophrenia; however, many others have not been able to confirm this. Because of the contradictory findings reported in various studies, more definitive research on this issue is required. Hence, we have investigated the NR1 subunit of NMDAR antibodies in patients with schizophrenia $(n=49)$ and healthy controls $(n=48)$. None of the investigated patients with schizophrenia and none of the healthy controls showed positive antibody against the NR1 subunit of the NMDAR. On the basis of this result, we conclude that the NR1 subunit of the NMDAR antibodies does not seem to have a role in schizophrenia.
\end{abstract}

Keywords: schizophrenia, $N$-acetyl D-aspartate receptor, glutamate, antibody

\section{Introduction}

Schizophrenia is a clinical syndrome characterized by certain cognitive, emotional, and behavioral symptoms and findings, and impaired self-care, self-sufficiency, communication, and professional functional abilities. ${ }^{1}$ The etiopathogenesis of schizophrenia is not clearly understood. It has been accepted as a multifactorial disease. ${ }^{2}$

A disease called anti-NMDAR encephalitis, which is an inflammatory brain disease, was defined recently. ${ }^{3}$ The prevalence of anti-NMDAR encephalitis is not known, but it was the most frequent cause of encephalitis of unknown origin. ${ }^{4}$ In a large series of 577 cases with anti-NMDAR encephalitis, 81\% were female. ${ }^{5}$ In this disease, antibodies are formed against the NR1 subunit of NMDAR within the blood and the cerebrospinal fluid (CSF). Anti-NMDAR encephalitis, which is commonly observed as a paraneoplastic syndrome, presents with impaired NMDAR functions as a result of these antibodies. ${ }^{3,6-8}$ The characteristic neuropsychiatric symptoms of this disease are compatible with the symptoms of schizophrenia. ${ }^{3,6,7}$

The compatibility of the characteristic neuropsychiatric symptoms of anti-NMDAR encephalitis with the symptoms of schizophrenia has directed the investigators to question the presence of NMDAR antibodies in patients with schizophrenia. However, conflicting results have been observed in the studies conducted. Some of these studies ${ }^{9-12}$ have not detected NMDAR antibodies in the blood or the CSF of patients with schizophrenia, while others have detected the antibodies at certain amounts and demonstrated male predominance $(\sim 70 \%) .{ }^{13-18}$ In studies reporting the presence of NMDAR antibodies in the serum, the rate of antibodies vary between $6 \%$ and $10 \%$ among patients with schizophrenia. ${ }^{13-18}$ These high rates should be confirmed in wider studies, which would then necessitate changes in the diagnosis and treatment protocols of schizophrenia. In this study, we investigated the presence of IgG-type antibodies formed against NMDAR NR1 in patients with schizophrenia and their role in the etiopathogenesis of the disease.
Correspondence: Damla Timucin Psikiyatri Bölümü, SB Sağlık Bilimleri Üniversitesi, Van Bolge Egitim ve Arastirma Hastanesi, 65100,

Edremit/Van, Turkey

Tel +90505 3878049

Email damlatimucin@gmail.com 


\section{Materials and method Study design}

This study was planned as a case-control investigation for the detection of antibodies formed against the NR1 subunit of NMDAR in the serum samples of patients with schizophrenia. The variables of the study group assessed were the age, sex, family history of psychological disorder, duration of the disease, stage of the disease, status of the antibodies formed against the NR1 subunit of serum NMDAR, the clinical global impression scale score, the Global Assessment Scale score, the Insight Assessment Scale score, the Quality of Life Scale for Schizophrenia score, the Negative Symptoms Assessment Scale score, and the Positive Symptoms Assessment Scale score.

\section{Participants}

This study included 49 patients diagnosed with schizophrenia and 48 healthy controls who had presented to the Van Yuzuncu Y1l University Medical Faculty Dursun Odabas Medical Center Psychiatry Department. Yuzuncu Y1l University ethics committee approved the study (Number: B.30.2.YY U.0.01.00.00/257), and all patients gave written informed consent.

Inclusion criteria for the study were the following:

1) Age between 18 and 65 years.

2) Diagnosed with schizophrenia for the study group according to the DSM-5.

3) No history of an immune disease or immunoregulator medication, no history of cancer or a terminal-stage chronic disease.

4) Absence of a systemic/metabolic disease that would affect neurological development, organic brain damage, mental retardation, or alcohol/substance addiction.

5) No history and no family history of diagnosed schizophrenia for the control group.

Those with a score of 25 and higher according to the Positive Symptoms Assessment Scale were considered to be in the acute stage of the disease.

\section{Evaluation of the blood samples}

\section{Sample collection}

The blood samples for the study and the control groups were obtained from the antecubital vein. No scheduled time or fasting condition was defined for the blood collection. The blood samples were placed into regular biochemistry tubes and centrifuged at $4,000 \times g$ for 10 minutes. The separated serum samples were transferred from room temperature, within a maximum of 4 hours, to $-80^{\circ} \mathrm{C}$, where they were kept until the time of the analysis. Similar storage procedures were used for both the patient and the control samples.
Detection of antibodies against glutamate receptors

Antibody tests for all antibodies (IgG-type antibodies formed against the NR1 subunit of NMDAR) were performed using a previously defined standard laboratory technique. ${ }^{19,20}$ The test system exclusively serves for the in vitro determination of human antibodies in human serum. Cell-based assays for those antibodies were performed using EU90 cells (Euroimmun AG, Luebec, Germany). The kits, referred to as Biochip by the manufacturer (Euroimmun), were incubated with the serum samples diluted as $1 / 10$ and $1 / 200$. The $1 / 10$ dilution rate was used for the blood samples of 24 patients (of whom 17 were in acute phase) and 24 controls, and a 1/200 dilution rate was used for the blood samples of 25 patients (of whom seven were in acute phase) and 24 controls. In the second step, Biochip slides were stained with fluorescein-labeled antihuman antibodies, and then the attached antibodies were made visible with the fluorescence microscope. Anti-glutamate receptor, type NMDA (rat cerebellum/hippocampus), was used as positive control according to the manufacturer's instructions. For each evaluation, a positive and negative control specimen was included to ensure consistency in test performance and interpretation. The samples were classified as positive or negative according to the immunofluorescence intensities of the transfected cells where immune reactions were visible (Figure 1).

\section{Statistical analysis}

The obtained data from the research were analyzed using the Stats Direct (ver 3.0.150, Stats Direct Limited, Altrincham, UK) software package. The descriptive statistics of all of the data in the study were calculated. The Kolmogorov-Smirnov test was used to assess whether the data had a normal distribution or not. The chi-square test was used to compare binary variables such as sex and the ratios between the patient and the control groups. Descriptive (percentage, arithmetic mean, standard deviation, and min-max) statistics were used to analyze the characteristics (sociodemographic data, scale scores) of the patients, while the Student's $t$-test was used to compare the parametric data. In the study, all of the results were assessed at a significance level of $P=0.05$.

\section{Results}

\section{Descriptive analysis of sociodemographic parameters}

A total of 49 patients with schizophrenia were included in the study. Among these, 13 were female (26.5\%) and 36 were male $(73.5 \%)$. The mean age and the age range were $35.9 \pm 13.6$ and 18-61 years, respectively. Among the 48 control group participants, 12 were female $(25 \%)$ and 36 were male. The mean age in the control group was $38.4 \pm 14.1$ years. No 

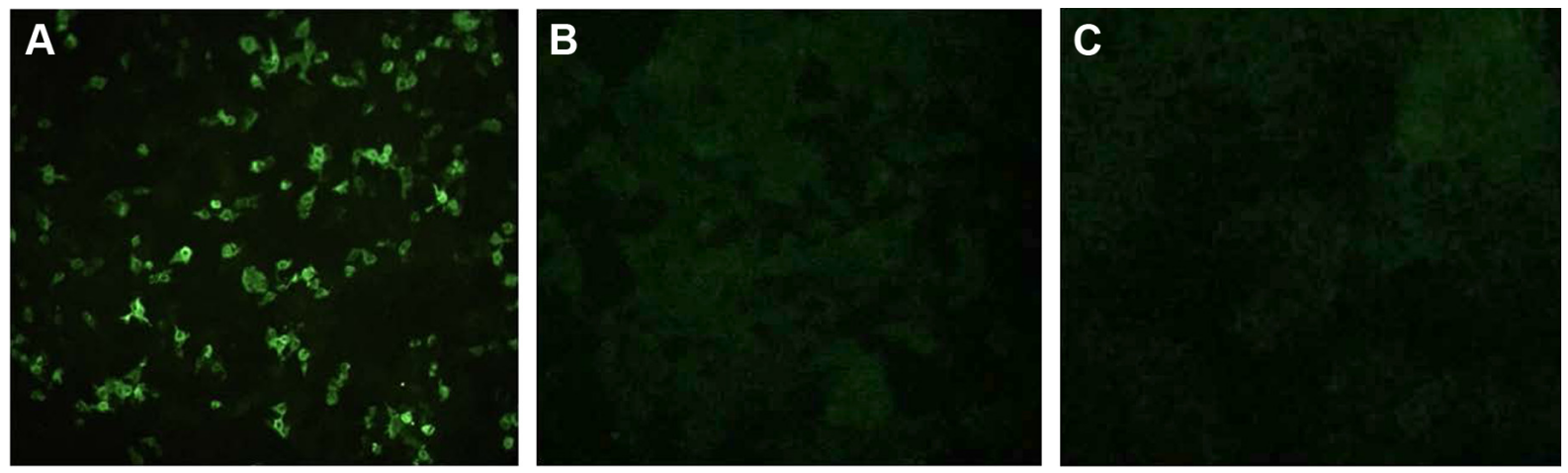

Figure I The NMDAR antibody reactivity in the serum samples as determined by immunofluorescence.

Notes: (A) Transfected control cells expressing glutamate receptor with positive reaction sign (NMDA; NRI subgroup). (B) Negative control group, nontransfected cells (negative reaction). (C) Glutamate receptor-expressing cells showing negative reaction with the serum of a patient with schizophrenia (NMDA; NRI subgroup) (negative reaction).

difference was observed between the patient and the control groups with regard to age and sex $(P>0.05)$. Forty-one patients were on typical and/or atypical antipsychotic drugs. Eight patients were not taking any medication. The mean duration of the disease in 49 patients with schizophrenia was 12.8 \pm 10.7 years (min: 1 year; max: 40 years). Twenty-one patients demonstrated acute symptoms of the disease during sample collection (Table 1).

\section{Antibody detection outcomes}

No specific signal for NMDAR was detected in the serological investigation of the serum samples obtained from the 49 patients with schizophrenia and the 48 healthy controls in either the $1 / 10$ or $1 / 200$ dilution (Figure 1 ). No anti-NR1 $\mathrm{IgG}$ antibody was observed in any of the groups.

\section{Discussion}

In a previous study, no NMDAR NR1 IgG antibody was detected in the serum samples of 80 patients fulfilling the diagnostic criteria of schizophrenia at the end of 1 year in their first psychotic attack. ${ }^{9}$ Rhoads et a ${ }^{10}$ conducted a similar study with a small sample size and detected no antibody either. Haussleiter et al $^{11}$ determined no NMDAR antibodies

Table I Mean and standard deviation data according to the scores observed in the scales in the schizophrenia group

\begin{tabular}{lll}
\hline $\begin{array}{l}\text { Patients with schizophrenia } \\
(\mathbf{n}=\mathbf{4 9})\end{array}$ & Mean & SD \\
\hline PSAS score & 26.3 & 17.8 \\
NSAS score & 53.6 & 27.7 \\
CGI score & 4.7 & 1.2 \\
IAS score & 10.3 & 5.8 \\
QLSS score & 57.7 & 26.4 \\
\hline
\end{tabular}

Abbreviations: PSAS, Positive Symptoms Assessment Scale; NSAS, Negative Symptoms Assessment Scale; CGI, Clinical Global Impression Scale; IAS, Insight Assessment Scale; QLSS, Quality of Life Scale for Schizophrenia; SD, standard deviation. in the serum samples of 44 psychosis patients, $\sim 75 \%$ of whom were in the chronic stage. Masopust et $\mathrm{al}^{12}$ demonstrated no antibody presence in any of the patient or the control groups in their study including 50 cases. In this study, we did not demonstrate the presence of any antibody either.

The presence of antibodies at varying rates has been reported in other studies. However, a very small rate of the NMDAR antibodies is of the NR1 IgG subtype, which has been shown to present anti-NMDAR encephalitisrelated schizophrenia-like symptoms. Zandi et $\mathrm{al}^{13}$ detected antibodies against the NR1 or NR2 NMDAR subunits in three out of 46 early-stage schizophrenia cases. In that study, a specific NMDAR subunit was not targeted (NR1 versus NR2), and no control group or control test was included in the study. Zandi et $\mathrm{al}^{21}$ explained that the antibody detection test they had used in their previous study had yielded an incorrect result in one of the three seropositive cases in another study they had conducted using the same antibody detection test. Therefore, they reported ${ }^{19}$ that a revision of their previous study data ${ }^{13}$ be performed. In a wider series study by Steiner et al, ${ }^{14}$ serum samples of 459 patients with schizophrenia, major depression, and borderline personality disorder were investigated. It is worth considering that two patients with a typical presence of antibodies and a classic anti-NMDAR encephalitis were reported to be followed up with a misdiagnosis of schizophrenia. ${ }^{14}$ IgA- and IgM-type antibodies against NR1/NR2 subunits had been detected in $\sim 10 \%$ of the patients with schizophrenia in that study. ${ }^{14}$ Although the presence of NMDAR antibodies and autoimmunity was suggested to be responsible for the symptoms of schizophrenia, the investigated antibody types and the NMDAR subunits were different from those defined for anti-NMDAR encephalitis. However, the study was repeated with a more sensitive antibody detection test, 
and it was demonstrated that the IgA and IgM antibody titers within the patient sera were similar to those of the control group. ${ }^{17}$ This study ${ }^{17}$ is similar to other large series studies including IgA- and IgM-type autoantibodies in both the patient and the control groups at a high rate $(\sim 10 \%) .{ }^{15,16}$ However, the presence of IgA- and IgM-type NMDAR antibodies at a high rate in both the patient and the control groups has opened the clinical importance of the antibody to question. . $2,23^{2}$

It has been reported that the stage of the disease affects the presence of NMDAR antibodies. ${ }^{19,24,25}$ When considering that the mean duration of disease in the patient group of our study was 12.2 years, the titers of NMDAR antibodies, which were probably present in the first episode psychosis, may have decreased in time. There are studies reporting significantly higher NMDAR antibody seropositivity in FEP patients without diagnosed schizophrenia compared to healthy controls. ${ }^{13,24,26}$ However, there are others demonstrating no difference. ${ }^{9,12,15-17}$ FEP patients who have presented for the first psychotic episode associated with a schizophrenia spectrum diagnosis were not included in our schizophrenia group. A relationship between the antibody titer and the severity of the clinical presentation in anti-NMDAR encephalitis has been observed. ${ }^{27}$ Our study included 24 patients considered to be in the acute phase of schizophrenia with no NMDAR antibody in the sera. We did not observe a relationship between the presence of NMDAR antibodies and the clinical presentations of the patients in the acute phase of the disease.

Detection of NMDAR antibody presence in healthy controls is controversial. A limited number of studies have reported the presence of NMDAR antibody in healthy controls at rates of $10.8 \%, n=137 ;^{15} 8.5 \%, n=145 ;{ }^{16}$ and $7 \%$, $\mathrm{n}=25,{ }^{17}$ whereas many of the studies, ${ }^{9-13,26}$ including ours, have detected no NMDAR antibody in healthy controls. Studies investigating the presence of NMDAR antibody in patients with primary anti-NMDAR encephalitis ${ }^{20,28,29}$ have also reported no detection of NMDAR antibody in the control groups. Therefore, the majority of the literature data have reported no presence of NMDAR antibodies in healthy controls. Some studies reporting positive NMDAR antibodies in healthy controls ${ }^{15,16,30}$ have contributed this seropositivity to the age factor. The mean age was $38.4 \pm 14.1$ years in our control group. No difference was observed between the patient and the control groups with regard to age in the study $(P>0.05)$. The mean age in control group was similar to those reported in the aforementioned studies $\left(40.9 \pm 12.2 \cdot{ }^{15}\right.$ $\left.37.7 \pm 13.5 ;{ }^{16} 36 \pm 1,217\right)$. Discussion continues on the subjects of investigating the antibody within the CSF and the role of the blood-brain barrier for the passage of antibodies into the CSF. ${ }^{15,31-35}$

The dilution rate affects the detectability of NMDAR antibodies. ${ }^{14,15}$ Low dilution rates give higher rates of antibody presence. ${ }^{14,15}$ However, the clinical importance of the difference between low and high dilution rates has not been defined yet. Currently, there is no clear information on the dilution rates other than the meta-analysis provided by Pearlman and Najjar ${ }^{36}$ in which the NMDAR antibody rates detected using high dilution rates in a group of patients with a psychiatric diagnosis including schizophrenia were three times more likely to have elevated NMDAR antibody titers compared with healthy controls. Therefore, the optimal dilution rate for distinguishing psychiatric patients from healthy controls via NMDAR antibody detection has not been precisely defined yet. No presence of antibody was detected in low and high dilution rates in our study groups.

Some authors suggest routine NMDAR antibody investigation for all patients presenting to clinics with psychosis. ${ }^{37}$ One of the aims of this clinical study was to investigate the necessity of routine NMDAR antibody determination in schizophrenic patients presenting with psychosis. However, antibody was negative in the patient group. Evidence-based reliable data for suggestion of NMDAR antibody detection in schizophrenic patients are still missing.

Although this study did not find any evidence of NMDAR antibodies in schizophrenia cases, there have been a number of studies reporting association between NMDAR antibodies and schizophrenia. These studies, overall, shift the weight of evidence in favor of a causal relationship between the evidence of NMDAR antibodies and schizophrenia. However, it may not be known whether the reported association is due to causation or correlation. Correlation may be due to genetic $^{38}$ and environmental factors ${ }^{39}$ that cannot be readily disentangled with this limited numbers of samples.

This study has many limitations. The first is the limited number of participants. The presence of NMDAR antibodies independent from anti-NMDAR encephalitis may be possible in some schizophrenic patients in studies including larger series. Therefore, our study has no evidence-based adequacy or power $(\sim 0.2)$ alone. Another limitation is that only the NR1 IgG subtype was investigated in the test. However, it is known that antibodies formed against other subunits of NMDAR accompany the psychotic presentation as well. Hence, these outcomes may be suggestive for the NR1 IgG subunit of NMDAR only. The final limitation is that the samples examined for antibody presence were only sera. The lack of concomitant CSF examination weakens the outcomes of this study. 
In this clinical study, we did not detect NMDAR antibody in schizophrenic patients or healthy controls at high dilution rates. Despite studies reporting seropositivity in the literature, NMDAR antibody was negative in both the patient and the control groups. Further studies with larger samples sizes are required for the investigation of the subject.

\section{Acknowledgment}

Damla Timucin thanks Yuzuncu Yil University Scientific Research Committee for the support granted to her research project thesis.

\section{Disclosure}

The authors report no conflicts of interest in this work.

\section{References}

1. American Psychiatric Association. Diagnostic and Statistical Manual of Mental Disorders. 5th ed. Washington, DC: American Psychiatric Association; 2013.

2. Lieberman AJ. Textbook of Schizophrenia. Washington, DC: The American Psychiatric Publishing; 2006:142-144.

3. Dalmau J, Gleichman AJ, Hughes EG, et al. Anti-NMDA-receptor encephalitis: case series and analysis of the effects of antibodies. Lancet Neurol. 2008;7(12):1091-1098.

4. Titulaer MJ, McCracken L, Gabilondo I, et al. Treatment and prognostic factors for long-term outcome in patients with antiNMDA receptor encephalitis: an observational cohort study. Lancet Neurol. 2013;12:157-165.

5. Gable MS, Sheriff H, Dalmau J, Tilley DH, Glaser CA. The frequency of autoimmune $N$-methyl-D-aspartate receptor encephalitis surpasses that of individual viral etiologies in young individuals enrolled in the California Encephalitis Project. Clin Infect Dis. 2012;54:899-904.

6. Vincent A, Bien CG. Anti-NMDA-receptor encephalitis: a cause of psychiatric, seizure, and movement disorders in young adults. Lancet Neurol. 2008;7(12):1074-1075.

7. Gable MS, Gavali S, Radner A, et al. Anti-NMDA receptor encephalitis: report of ten cases and comparison with viral encephalitis. Eur J Clin Microbiol Infect Dis. 2009;28(12):1421-1429.

8. Hughes EG, Peng X, Gleichman AJ, et al. Cellular and synaptic mechanisms of anti-NMDA receptor encephalitis. $J$ Neurosci. 2010;30(17): 5866-5875.

9. Masdeu JC, Gonzalez-Pinto A, Matute C, et al. Serum IgG antibodies against the NR1 subunit of the NMDA receptor not detected in schizophrenia. Am J Psychiatry. 2012;169:1120-1121.

10. Rhoads J, Guirgis H, McKnight C, Duchemin AM. Lack of anti-NMDA receptor autoantibodies in the serum of subjects with schizophrenia. Schizophr Res. 2011;129:213-214.

11. Haussleiter IS, Emons B, Schaub M, et al. Investigation of antibodies against synaptic proteins in a cross-sectional cohort of psychotic patients. Schizophr Res. 2012;140:258-259.

12. Masopust J, Andrýs C, Bažant J, Vyšata $\mathrm{O}$, Kuca K, Vališ M. AntiNMDA receptor antibodies in patients with a first episode of schizophrenia. Neuropsychiatr Dis Treat. 2015;6(11):619-623.

13. Zandi MS, Irani SR, Lang B, et al. Disease-relevant autoantibodies in first episode schizophrenia. J Neurol. 2011;258:686-688.

14. Steiner J, Walter M, Glanz W, et al. Increased prevalence of diverse $\mathrm{N}$-methyl-D-aspartate glutamate receptor antibodies in patients with an initial diagnosis of schizophrenia: specific relevance of IgG NR1a antibodies for distinction from $N$-methyl-D-aspartate glutamate receptor encephalitis. JAMA Psychiatry. 2013;70:271-278.
15. Hammer C, Stepniak B, Schneider A, et al. Neuropsychiatric disease relevance of circulating anti-NMDA receptor autoantibodies depends on blood-brain barrier integrity. Mol Psychiatry. 2014;19:1143-1149.

16. Dahm L, Ott C, Steiner J, et al. Seroprevalence of autoantibodies against brain antigens in health and disease. Ann Neurol. 2014;76:82-94.

17. Steiner J, Teegen B, Schiltz K, Bernstein HG, Stoecker W, Bogerts B. Prevalence of $N$-methyl-D-aspartate receptor autoantibodies in the peripheral blood: healthy control samples revisited. JAMA Psychiatry. 2014;71:838-839.

18. Tsutsui K, Kanbayashi T, Tanaka K, et al. Anti-NMDA-receptor antibody detected in encephalitis, schizophrenia, and narcolepsy with psychotic features. BMC Psychiatry. 2012;12:37.

19. Planagumà $\mathrm{J}$, Leypoldt $\mathrm{F}$, Mannara $\mathrm{F}$, et al. Human $N$-methyl-Daspartate receptor antibodies alter memory and behavior in mice. Brain. 2015;138(Pt 1):94-109.

20. Wandinger KP, Dalmau J, Borowski K, et al. Pathogenesis to Therapy of Autoimmune Diseases. Autoantigens, Autoantibodies, Autoimmunity. Lengerich, Germany: Pabst Science Publishers; 2009;6:434-435.

21. Zandi MS, Paterson RW, Ellul MA, et al. Clinical relevance of serum antibodies to extracellular $N$-methyl-D-aspartate receptor epitopes. J Neurol Neurosurg Psychiatry. 2015;86(7):708-713.

22. Titulaer MJ, Dalmau J. Antibodies to NMDA receptor, blood-brain barrier disruption and schizophrenia: a theory with unproven links. Mol Psychiatry. 2014;19(10):1054.

23. Ehrenreich H, Steiner J. Serum autoantibodies against $N$-methyl-Daspartate receptor subunit NR1 are no disease indicator. Ann Neurol. 2015;77(1):184.

24. Govorin NV, Vasil'eva AI. Effect of haloperidol and risperidone on neuromarkers and indices of endothelial dysfunction in patients with acute schizophrenia. Zh Nevrol Pyschiatry Im S S Korsakova. 2011; 111(3):54-57. Russian.

25. Dickerson F, Stallings C, Origoni A, et al. A combined marker of inflammation in individuals with mania. PLoS One. 2013;8 (9):e73520.

26. Pathmanandavel K, Starling J, Merheb V, et al. Antibodies to surface dopamine-2 receptor and $N$-methyl-D-aspartate receptor in the first episode of acute psychosis in children. Biol Psychiatry. 2015;77(6): 537-547.

27. Kayser MS, Titulaer MJ, Gresa-Arribas N, Dalmau J. Frequency and characteristics of isolated psychiatric episodes in anti- $N$-methyl-Daspartate receptor encephalitis. JAMA Neurol. 2013;70(9):1133-1139.

28. Irani SR, Bera $\mathrm{K}$, Waters $\mathrm{P}$, et al. $N$-methyl-D-aspartate antibody encephalitis: temporal progression of clinical and paraclinical observations in a predominantly non-paraneoplastic disorder of both sexes. Brain. 2010;133:1655-1667.

29. Dalmau J, Tüzün E, Wu H, et al. Paraneoplastic anti- $N$-methyl-Daspartate receptor encephalitis associated with ovarian teratoma. Ann Neurol. 2007;61:25-36.

30. Busse S, Busse M, Brix B, et al. Seroprevalence of $N$-methyl-D-aspartate glutamate receptor (NMDA-R) autoantibodies in aging subjects without neuropsychiatric disorders and in dementia patients. Eur Arch Psychiatry Clin Neurosci. 2014;264:545-550.

31. Gresa-Arribas N, Titulaer MJ, Torrents A, et al. Antibody titres at diagnosis and during follow-up of anti-NMDA receptor encephalitis: a retrospective study. Lancet Neurol. 2014;13(2):167-177.

32. Lauvsnes MB, Omdal R. Systemic lupus erythematosus, the brain, and anti-NR2 antibodies. J Neurol. 2012;259:622-629.

33. Diamond B, Huerta PT, Mina-Osorio P, Kowal C, Volpe BT. Losing your nerves? Maybe it's the antibodies. Nat Rev Immunol. 2009;9: $449-456$.

34. Zlokovic BV. The blood-brain barrier in health and chronic neurodegenerative disorders. Neuron. 2008;57:178-201.

35. Brimberg L, Sadiq A, Gregersen PK, Diamond B. Brain-reactive IgG correlates with autoimmunity in mothers of a child with an autism spectrum disorder. Mol Psychiatry. 2013;18:1171-1177.

36. Pearlman DM, Najjar S. Meta-analysis of the association between $\mathrm{N}$-methyl-D-aspartate receptor antibodies and schizophrenia, schizoaffective disorder, bipolar disorder, and major depressive disorder. Schizophr Res. 2014;157(1-3):249-258. 
37. Lennox BR, Coles AJ, Vincent A. Antibody-mediated encephalitis: a treatable cause of schizophrenia. Br J Psychiatry. 2012;200:92-94.

38. Mehta D, Tropf FC, Gratten J, et al. Evidence for genetic overlap between schizophrenia and age at first birth in women. JAMA Psychiatry. 2016;73:497-505.
39. Santos CM, Peres FF, Diana MC, et al. Peripubertal exposure to environmental enrichment prevents schizophrenia-like behaviors in the SHR strain animal model. Schizophr Res. Epub June 21, 2016.

\section{Publish your work in this journal}

Neuropsychiatric Disease and Treatment is an international, peerreviewed journal of clinical therapeutics and pharmacology focusing on concise rapid reporting of clinical or pre-clinical studies on a range of neuropsychiatric and neurological disorders. This journal is indexed on PubMed Central, the 'PsycINFO' database and CAS, and is the official journal of The International Neuropsychiatric Association (INA). The manuscript management system is completely online and includes a very quick and fair peer-review system, which is all easy to use. Visit http://www.dovepress.com/testimonials.php to read real quotes from published authors.

\footnotetext{
Submit your manuscript here: http://www.dovepress.com/neuropsychiatric-disease-and-treatment-journal
} 